\title{
Optimization of Effects of Pocket Tool Path Strategies and Cutting Parameters on Surface Quality
}

\author{
A. ETyemez*
}

Nikken Turkey, Kucukyali Is Merkezi Maltepe, 34852 İstanbul, Turkey

\begin{abstract}
In this study, surface roughness and cutting forces were investigated experimentally in milling of $\mathrm{Al} 7075$ material by DLC coated end-mill cutting tools. Effect of tool path, feed and cutting depths on surface roughness and cutting forces was examined. Taguchi technique was used for optimization of the milling process. Also, a variance analysis (ANOVA) was used for determination of effect of each parameter on the obtained results. In conclusion, the relationship between the dependent and the independent variables was modelled with regression analysis. Optimal machinability of Al 7075 material by DLC coated end-mill was determined in this study.
\end{abstract}

DOI: 10.12693/APhysPolA.129.886

PACS/topics: $81.20 . \mathrm{Wk}$

\section{Introduction}

Among the modern machining tools, CNC milling machines are extensively used in machining. Various CAM software programs are used for programming CNC milling machines, which are used in cast manufacturing as well as machining of many products. Tool path machining programs are introduced by using these software while many forms, such as one-way, zigzag, spiral, etc., are proposed for the machining path. Selection of these methods affects also machining time and surface quality of the machined material [1-3].

High-strength materials are achieved with the developments in materials technology. It is required to choose a suitable cutting tool among these materials in order to provide the maximum efficiency during machining $[1,4-8]$. Determination of the material of the tool and the cutting geometry is very essential. Efficiency is reduced when the machining conditions are non-standard, even if the suitable tool is selected. Theoretical studies should be carried out for each material to be machined and each type of cutting tools in order to provide high efficiency and to be able to make economical machining $[1,2,6-10]$. It is specified that determination and application of cutting tool strategies and movements are critical in milling of volume casts, aeronautical and cutting casts [1-5]. Selection of the suitable cutting strategy and movement provides a reduced machining time and production cost and an increased surface quality, tool life, and efficiency. In particular, tool displacement types affect the cutting forces. It was indicated that tool displacement errors should be minimized in order to reduce the occurring cutting forces.

In this study, surface roughness and cutting forces were investigated experimentally in milling of $\mathrm{Al} 7075$ aluminum material (which is used in many fields such

\footnotetext{
*e-mail: ayhan.etyemez@marmara.edu.tr
}

as space and aircraft industry) by DLC coated endmill cutting tools. Effect of tool path, feed and cutting depths on surface roughness and cutting forces was examined. Taguchi technique was used for optimization of the milling process. Also, a variance analysis (ANOVA) was used for determination of effect of each parameter on the obtained results. In conclusion, the relationship between the dependent and the independent variables was modeled with regression analysis.

\section{Materials and methods}

\subsection{Test specimens and experimental setup}

Specimens used in the experimental study are made of Al 7075 aluminum alloy, chemical compositions and mechanical characteristics of which are given in Table I and Table II, respectively.

TABLE I

Chemical composition of Al 7075.

\begin{tabular}{c|c|c|c|c|c|c}
\hline \hline $\mathrm{Al}$ & $\mathrm{Cu}$ & $\mathrm{Mn}$ & $\mathrm{Si}$ & $\mathrm{Ti}$ & $\mathrm{Zn}$ & $\mathrm{Cr}$ \\
\hline Base & 2.0 & 0.30 & 0.13 & 0.20 & 0.5 & 0.28
\end{tabular}

TABLE II

Mechanical characteristics of $\mathrm{Al} 7075$.

\begin{tabular}{c|c|c|c|c}
\hline \hline $\begin{array}{c}\text { Tensile } \\
\text { strength } \\
{[\mathrm{Mpa}]}\end{array}$ & $\begin{array}{c}\text { Yield } \\
\text { strength } \\
{[\mathrm{Mpa}]}\end{array}$ & $\begin{array}{c}\text { Elongation } \\
{[\%]}\end{array}$ & $\begin{array}{c}\text { Density } \\
{\left[\mathrm{kg} / \mathrm{m}^{3}\right]}\end{array}$ & $\begin{array}{c}\text { Hardness } \\
{[\mathrm{HB}]}\end{array}$ \\
\hline 570 & 505 & 11 & 2800 & 160
\end{tabular}

The following equipment was used in the experiments: JOHNFORD VMC-850/550+APC CNC Fanuc 0T x-y-z axis CNC Milling Machine, DLC-mill L9330 DLC coated end-mill, MAHR-Perthometer surface roughness tool for surface roughness measurement, KISTLER 9265B dynamometer for cutting force measurement, KISTLER 5019b type charge amplifier and DynoWare software for the analysis. 


\subsection{Experimental design and measurement}

Experiment was designed by using the Taguchi technique. This way, it was possible to achieve more comprehensive results with smaller number of experiments. Thus, time and costs have been saved. As the measured surface roughness and the cutting force rates are required to be minimal in determination of the quality characteristics, the principle "the smallest is the best" was used for the quality values expected to be found as a result of the experiments. In this experimental study,

TABLE III

Experimental Variables.

\begin{tabular}{c|c|c|c}
\hline \hline Parameters & $\begin{array}{c}(\mathrm{A}) \\
\text { Tool path }\end{array}$ & $\begin{array}{c}(\mathrm{B}) \\
\text { Feed } \\
{[\mathrm{mm} / \mathrm{min}]}\end{array}$ & $\begin{array}{c}(\mathrm{C}) \\
\text { Cutting depth } \\
{[\mathrm{mm}]}\end{array}$ \\
\hline Level I & One-way & 500 & 0.25 \\
Level II & Zig-zag & 650 & 0.50 \\
Level III & Spiral & 800 & 0.75
\end{tabular}

TABLE IV

$\mathrm{L}_{9}$ Experimental setup, surface roughness and cutting force values.

\begin{tabular}{c|c|c|c|c|c|c}
\hline \hline $\begin{array}{c}\text { Exp. } \\
\text { no. }\end{array}$ & Variables & $\begin{array}{c}(\mathrm{A}) \\
\text { Tool } \\
\text { path }\end{array}$ & $\begin{array}{c}(\mathrm{B}) \\
\text { Feed } \\
{[\mathrm{mm} / \mathrm{min}]}\end{array}$ & $\begin{array}{c}(\mathrm{C}) \\
\text { Cutting } \\
\text { depth } \\
{[\mathrm{mm}]}\end{array}$ & $\begin{array}{c}R_{a} \\
{[\mu \mathrm{m}]}\end{array}$ & $\begin{array}{c}\text { Cutting } \\
\text { force } \\
{[\mathrm{N}]}\end{array}$ \\
\hline 1 & $\mathrm{~A}_{1} \mathrm{~B}_{1} \mathrm{C}_{1}$ & 1 & 1 & 1 & 0.319 & 30.76 \\
2 & $\mathrm{~A}_{1} \mathrm{~B}_{2} \mathrm{C}_{2}$ & 1 & 2 & 2 & 0.435 & 33.69 \\
3 & $\mathrm{~A}_{1} \mathrm{~B}_{3} \mathrm{C}_{3}$ & 1 & 3 & 3 & 0.820 & 37.99 \\
4 & $\mathrm{~A}_{2} \mathrm{~B}_{1} \mathrm{C}_{2}$ & 2 & 1 & 2 & 0.450 & 28.98 \\
5 & $\mathrm{~A}_{2} \mathrm{~B}_{2} \mathrm{C}_{3}$ & 2 & 2 & 3 & 0.516 & 34.32 \\
6 & $\mathrm{~A}_{2} \mathrm{~B}_{3} \mathrm{C}_{1}$ & 2 & 3 & 1 & 0.633 & 35.33 \\
7 & $\mathrm{~A}_{3} \mathrm{~B}_{1} \mathrm{C}_{3}$ & 3 & 1 & 3 & 0.433 & 23.42 \\
8 & $\mathrm{~A}_{3} \mathrm{~B}_{2} \mathrm{C}_{1}$ & 3 & 2 & 1 & 0.507 & 24.52 \\
9 & $\mathrm{~A}_{3} \mathrm{~B}_{3} \mathrm{C}_{2}$ & 3 & 3 & 2 & 0.725 & 26.28
\end{tabular}

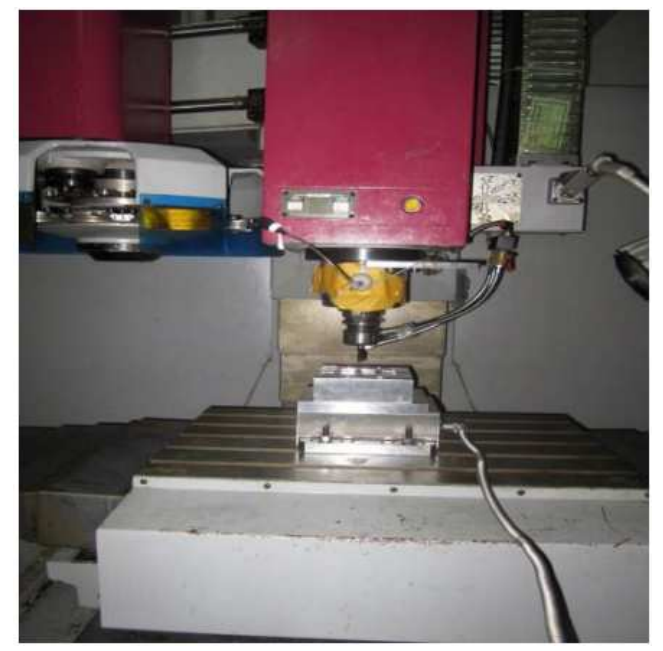

Fig. 1. Experimental setup. tool path, feed and cutting depths were chosen as parameters. Multiple-layer DLC coated end-mills were used in all experiments. The parameters and their values are presented in Table III, while L9 experimental design and the surface roughness and cutting forces obtained from the experiments are given in Table IV. Experimental setup is sketched in Fig. 1.

\section{Results and discussion}

\subsection{Signal-to-noise ratios and optimum levels}

Results obtained from Taguchi design are converted to the signal-to-noise $(\mathrm{S} / \mathrm{N})$ ratios and given in decibels $(\mathrm{dB})$. Signal represents the actual value to be measured, which is given by the system and the noise is the rate of undesirable factors within the measured value [11]. As the purpose is to achieve the minimum gradient in our study, the equation used for the signal-to-noise ratio was the equation "the smallest is the best" $[11,12]$.

$$
S / N=10 \log \left(\frac{1}{n} \sum_{i=1}^{n} y_{i}^{2}\right) .
$$

\subsection{Evaluation of the surface roughness results}

One of the subjects addressed in the experimental study was roughness of machined surfaces. Parameters affecting the formation of surface roughness have been well specified as a result of studies conducted for many years and, moreover, empirical equations comprising these parameters have been derived

$$
R_{a}=\frac{f r^{2} 1000}{4 D},
$$

where $R_{a}$ is surface roughness, $f$ is the feed, $r$ is the tip radius and $D$ is the diameter of cutting tool. As can be seen from Eq. 2, surface roughness value increases with the increasing feed value and decreases with the increasing cutting tool tip radius. However, this is a very general equation. Results obtained from our study are consistent with this equation. In general, the obtained surface roughness value is between $0.319-0.82 \mu \mathrm{m}$ and these values satisfy the expectations.

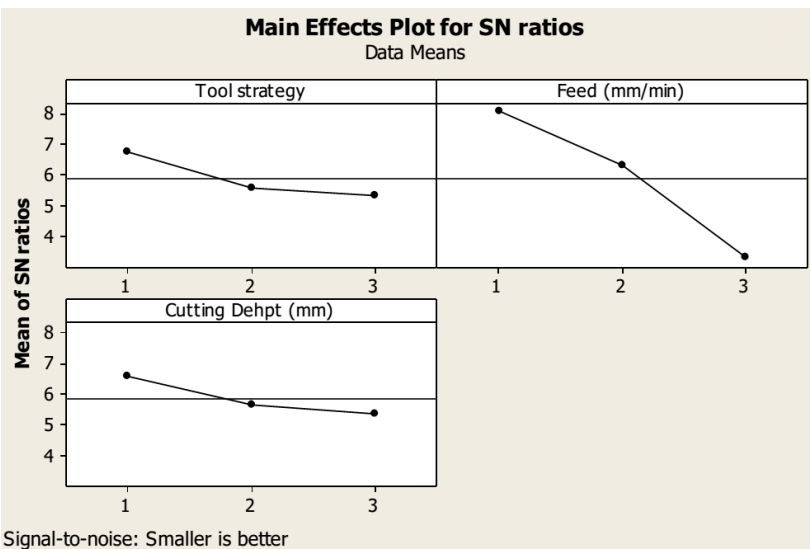

Fig. 2. $\mathrm{S} / \mathrm{N}$ ratios of surface roughness values. 


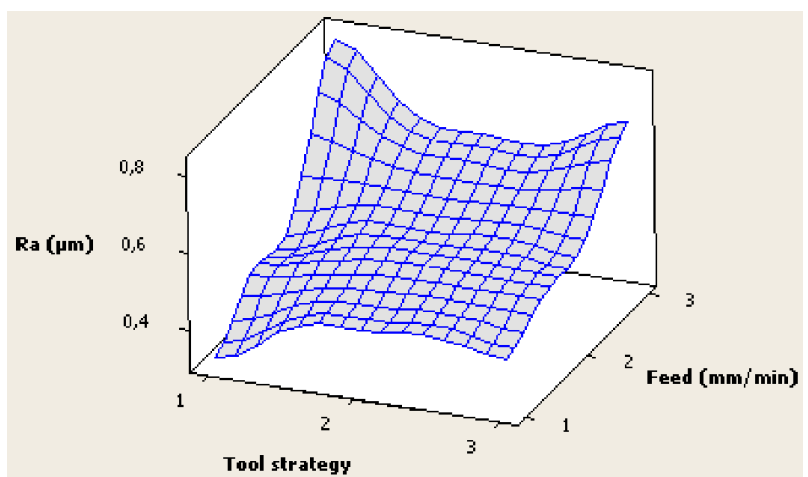

Fig. 3. Effects of tool path and feed on the surface roughness.

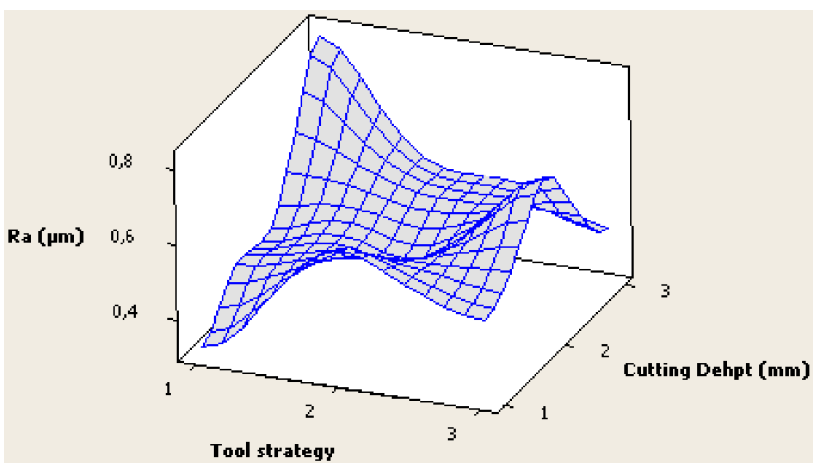

Fig. 4. Effects of cutting depth and tool path on the surface roughness.

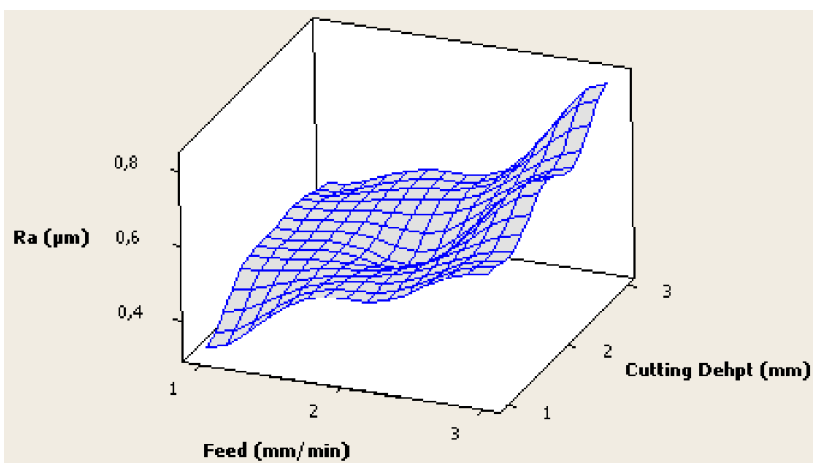

Fig. 5. Effects of cutting depth and feed on the surface roughness.

Contour Plot of Ra ( $\mu \mathrm{m})$ vs Tool strategy; Feed $(\mathrm{mm} / \mathrm{min})$

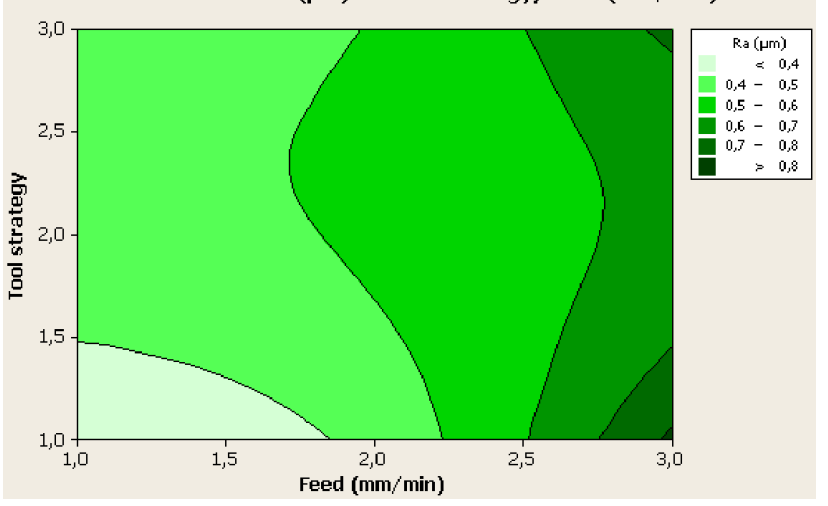

Fig. 6. Contour plot of the surface roughness.
$\mathrm{S} / \mathrm{N}$ ratios found as a result of the nine conducted experiments are given in Fig. 2. It is understood that the optimal surface quality is obtained when the machining parameters are as follows: one-way tool path, $500 \mathrm{~mm} / \mathrm{min}$ feed and $0.25 \mathrm{~mm}$ cutting depth. This situation shows that variation of $R_{a}$ is considerably affected by the feed and the tool path, whereas it does not depend completely on other parameters. Parameters affecting the surface roughness are depicted in the following figures (Figs. 3-6).

\subsection{Variance analysis}

Nine experiments were performed in milling of Al 7075 material using three different factors at three different levels, and, at the end of each experiment, $R_{a}$ response values were found to be different from each other. Variance analysis was used in order to specify whether these variations are purely coincidental or they result from the factors and determine effect of each factor on the response. As given in Table V and Fig. 7, the most effective factor is the feed with a value of $89.81 \%$ in formation of roughness on the machined surface, as a result of $\mathrm{Al} 7075$ material machined by DLC coated cutting tool.

TABLE V

ANOVA results depending on $R_{a}$ values.

\begin{tabular}{c|c|c|c|c|c}
\hline \hline Notations & $\begin{array}{c}\text { Degree } \\
\text { of } \\
\text { freedom }\end{array}$ & $\begin{array}{c}\text { Sum } \\
\text { of } \\
\text { squares }\end{array}$ & Variables & $f$ rate & $\begin{array}{c}\text { Percentage } \\
{[\%]}\end{array}$ \\
\hline $\mathrm{A}$ & 2 & 0.007926 & 0.003963 & 1.97 & 5.56 \\
$\mathrm{~B}$ & 2 & 0.128051 & 0.064025 & 31.82 & 89.81 \\
$\mathrm{C}$ & 2 & 0.006613 & 0.003306 & 1.64 & 4.62 \\
Error (e) & 2 & 0.004025 & 0.002012 & & 0.01 \\
Total & 8 & 0.146614 & & & 100
\end{tabular}

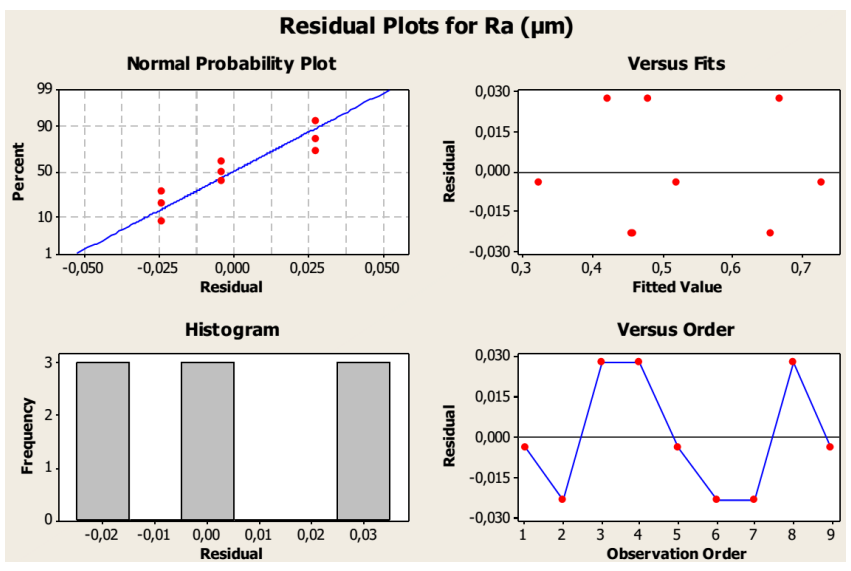

Fig. 7. Residual analysis of the model constituted for the surface roughness.

\subsection{Regression analysis}

Linear regression analysis was used in order to generate the estimating equation between the control factors (tool path, feed and cutting depth) used for machining 
and that of respond (mean surface roughness) and to be able to define the relationship between them. The obtained equation for the $R_{a}$ in this experimental study is given below

$$
\begin{aligned}
& R_{a}(\mu \mathrm{m})=0.106+0.0355 A+0.142 B \\
& \quad+0.0313 C+(\varepsilon) R^{2}=0.921,
\end{aligned}
$$

where $A$ is tool path, $B$ is feed and $C$ is cutting depth. Also, $\varepsilon$ gives the error. Value of $R^{2}$ which is the coefficient of determination of the equation of surface roughness was found to be 0.921 . Value of $R^{2}$ approaching 1 reflects proximity of the estimation model to the real relationship and the case where $R^{2}$ value equals to 0.8 and above is accepted as a strong relationship. As $\mathrm{R}^{2}$ in the estimating equation obtained from this study is above 0.8 , it is within the acceptable limits and has a strong relationship.

\section{Conclusions}

Useful results were obtained from this study in which machinability of Al 7075 material with DLC coated edges was investigated. Criteria taken into account for machinability were surface roughness and cutting force. Three control factors (tool path, feed and cutting depth) which are considered to be effective for realization of these criteria at the most ideal conditions were chosen at three different levels and applied in the experimental study. The obtained results are summarized as follows:

- The most effective factor in machining of $\mathrm{Al} 7075$ material with DLC cutting tools, affecting the value of surface roughness occurred on the machined surface, is the feed. The optimal surface roughness value is obtained when the machining parameters are as follows: one-way tool path, $500 \mathrm{~mm} / \mathrm{min}$ feed and $0.25 \mathrm{~mm}$ cutting depth.

- As a result of the performed study, Taguchi optimization technique was found to be an efficient technique in experimental study of Al 7075 material machinability, for optimization of the parameters and to provide response values range at the desired rates.

- The issue with respect what significance level each of the control factors has in obtaining the results from the experimental study was determined successfully by the variance analysis (ANOVA). According to that, feed is noticeable with a value of $89.81 \%$ in formation of roughness.
- The $R_{a}$ estimating equation was obtained with an accuracy of $92.1 \%$ by regression analysis for such an experimental study.

- When the obtained results are evaluated by considering also the literature, it is found that DLC coatings made positive contribution to machinability of Al 7075 material and, in particular, have accelerated the improvement of the cutting tool performance. Another result obtained from this study is that $\mathrm{Al} 7075$ material can be machined by dry milling with DLC coating.

\section{References}

[1] K.M.Y. Law, A. Geddam, V.A. Ostafiev, J. Mater. Process. Tech. 89-90, 238 (1999).

[2] C.K. Toh, J. Mater. Process. Tech. 152, 346 (2004).

[3] L.O. Sotiris, A.C. Nearchoub, Robot. CIM 25, 73 (2009).

[4] V. Pateloup, E. Duc, P. Ray, Int. J. Mach. Tool. Manu. 44, 1343 (2004).

[5] B.K. Hinds, T.S. Ong, J. Mater. Process. Tech. 152 , 339 (2004).

[6] A.K.M. Nurul Amina, S.B. Dolaha, M.B. Mahmuda, M.A. Lajis, J. Mater. Process. Tech. 201, 466 (2008).

[7] L.C. Brandao, R.T. Coelho, A.R. Rodrigues, J. Mater. Process. Tech. 199, 234 (2008).

[8] C. Tsao, H. Hocheng, J. Mater. Process. Tech. 123, 1 (2002).

[9] J.A. Arsecularatne, L.C. Zhang, C. Montross, P. Mathew, J. Mater. Process. Tech. 171, 244 (2006).

[10] J.A. Ghani, I.A. Choudhury, H.H. Masjuki, J. Mater. Process. Tech. 153-154, 1062 (2004).

[11] S. Mezarciöz, R.T. Oğulata, Tekstil Ve Konfeksiyon, 2010, p. 4.

[12] N. Sakarya, C. Göloğlu, Gazi Üniv. Müh. Mim. Fak. Der. 21, 603 (2006). 